FOCUS ON...

\title{
Battlefield Use Of Depleted Uranium And The Health Of Veterans
}

\author{
JPG Bolton, CRM Foster
}

This paper has already been published in Trauma.

\begin{abstract}
Depleted uranium munitions have been used in recent military operations in both the Gulf and the Balkans and there have been concerns that exposure to depleted uranium may be a cause of 'Gulf War Syndrome' and cancer clusters. We recount the properties of depleted uranium, its military uses and the situations in which personnel may be exposed. Following a review of scientific literature, the health effects of depleted and natural uranium exposure are described and the major outcomes of research into Gulf Veterans' Illnesses are summarised. We conclude that, although there is the potential for uranium exposures to cause renal damage or lung cancer, the risk of harm following depleted uranium exposure in military settings seems to be low. We advise on the management of casualties exposed to depleted uranium and suggest control measures that may be appropriate to protect personnel who provide casualty care.
\end{abstract}

Keywords: depleted uranium; gulf war syndrome; munitions; shrapnel.

\section{Introduction}

Depleted Uranium (DU) munitions were first used on the battlefield during the Gulf Conflict of 1991. Following that conflict some veterans have complained of nonspecific ill-health which they attribute to their service in the Gulf and to a number of associated exposures including DU. There have also been persistent allegations in the press of an increasing incidence of cancers among the civilian population in Southern Iraq. This has been ascribed to the use of DU during the Gulf conflict but without any epidemiological corroboration. In early 2001 the issue resurfaced with many stories in the media associating cancers and other illnesses among military veterans of peacekeeping operations in the Balkans where DU munitions had again been used. As a result of the concerns, a considerable amount of work has been undertaken which examines the health implications of the military use of DU munitions.

In this article, the properties of DU are described, as are exposure scenarios and environmental assessments. The evidence relating to the health effects of uranium and DU are then reviewed and advice is given on the management of casualties exposed to DU including the protection of medical personnel.

\section{Depleted Uranium \\ Properties}

Uranium has been mined since the Middle Ages but only with the advent of the nuclear age in the last 50-60 years has it been used on a large scale. It is a dense, weakly radioactive element which is found widely distributed throughout the natural environment. It is pyrophoric in that in small particles it burns readily in air. It predominantly consists of three radioactive isotopes ${ }^{234} \mathrm{U},{ }^{235} \mathrm{U}$ and ${ }^{238} \mathrm{U}$ and its main use is as a nuclear fuel for which purpose it has to be "enriched" (1). The enrichment process involves increasing the proportions of the more radioactive isotopes, ${ }^{234} \mathrm{U}$ and ${ }^{235} \mathrm{U}$, and decreasing the proportion of the less radioactive ${ }^{238} \mathrm{U}$. The less radioactive uranium by-product of the enrichment process is known as depleted uranium (2). The typical proportions, by weight, of uranium isotopes in natural and depleted uranium are shown in Table 1 . It can be seen that the difference between natural and depleted uranium in terms of the isotopic composition is actually very small since ${ }^{238} \mathrm{U}$ forms over $99 \%$ by weight of each substance.

Table 1. Comparison of Proportions of Uranium Isotopes by Weight

\begin{tabular}{|c|c|c|}
\hline Isotope & $\begin{array}{c}\text { Natural } \\
\text { Uranium }\end{array}$ & $\begin{array}{c}\text { Depleted } \\
\text { Uranium }\end{array}$ \\
\hline${ }^{234} \mathbf{U}$ & $0.0054 \%$ & $0.0006 \%$ \\
\hline${ }^{235} \mathbf{U}$ & $0.72 \%$ & $0.2 \%$ \\
\hline${ }^{238} \mathbf{U}$ & $99.27 \%$ & $99.8 \%$ \\
\hline
\end{tabular}

Uranium is primarily a weak alpha-particle emitter, but the removal, by the enrichment process, of the more active uranium isotopes renders DU some $40 \%$ less radioactive than in its naturally occurring form. Natural, enriched and depleted uranium can be regarded as being chemically identical. Even though isotopes of an element have different numbers of neutrons, their electron configurations are identical and there is, therefore, no difference in their chemical activity in biological systems.

Uses

The main use of uranium is in its enriched form in the nuclear industry but the density, low radioactivity and comparative inertness of DU are properties that give it commercial 


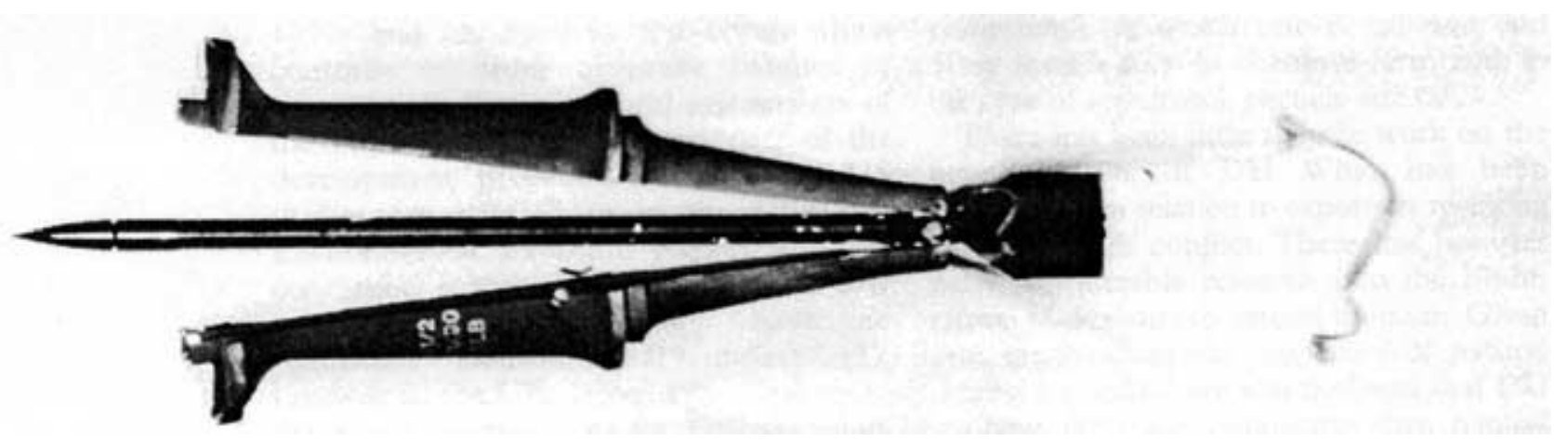

Fig 1. A typical tank-fired anti-tank round.

and military applications. Natural uranium has been used as a colouring in the glass and ceramics industries and DU was used in dental porcelain until the early 1980 s. DU is also used as a chemical catalyst in the oil and gas industry, for radiation shielding in the medical, research and transport industries and as counterweights and ballast in the marine and aerospace industries (1).

The high density and melting point of DU make it a highly effective armour against anti-tank weapons. It was used in this manner by the US to up-armour their Abrams tanks during the Gulf conflict. It proved its effectiveness in that Iraqi fire never penetrated such tanks (3).

Another property of DU is its ability to adiabatically shear (self-sharpen) and this, in conjunction with its high density, makes it a highly penetrative anti-armour munition. It is currently available in $25 \mathrm{~mm}, 30 \mathrm{~mm}$, $105 \mathrm{~mm}$ and $120 \mathrm{~mm}$ anti-armour rounds used by aircraft, tanks and on ship antimissile systems $(1,3)$. A typical tank-fired anti-tank round is shown at Figure 1 with the DU penetrator separating from its sabot as it would do in flight.

\section{Exposure Situations}

Whilst uranium is ubiquitously distributed in the environment, the main exposures to DU follow its military use. DU munitions have been fired on test ranges in the course of their development and to prove batches of ammunition. The first battlefield use of DU was in the Gulf conflict of 1991 when some 300 tonnes was fired by US and UK forces. The bulk of the DU (250 tonnes, 780,000 rounds) was fired from aircraft cannon; the rest was fired by tanks (3). The Iraqi forces did not have DU munitions but some US casualties resulted from friendly-fire incidents involving DU. There is no record of UK involvement in friendly fire incidents using DU. Aircraft-fired DU munitions were also used in the Balkans conflicts. US aircraft fired some 10,000 rounds (2.75 tonnes) in Bosnia during 1994-5 and 31,000 (8.5 tonnes) in Kosovo in 1999 (4). The Serbians did not use DU in the Balkans. The WHO has documented a typical aircraft-fired burst based on operations in Kosovo (5). A typical burst consists of 300 rounds of which $80 \%$ are DU. About $10 \%$ hit the target and $82 \%$ land within 100 metres. The remainder land within $1.85 \mathrm{~km}$. US work has shown that when a DU munition hits a hard target such as a main battle tank, it fragments and some of it burns forming aerosols of DU oxides. However, if the munition hits a soft skinned or lightly armoured target (light tank or armoured personnel carrier) it tends to pass through relatively intact (3). Harley has reported that $10-35 \%$ of a DU penetrator aerosolises in the manner described above (6).

Military exposure to DU therefore results from handling the munitions, being protected by the armour or being exposed following its use on the battlefield. Skin contact with intact munitions or armour will not impose a toxicological hazard and the external radiation hazard is minimal. It has been estimated that being in a DU-armoured closed-down tank carrying a full load of DU munitions for a full year would result in less than $25 \%$ of the US annual occupational exposure limit for ionising radiations and that it would require 250 hours of direct skin contact to exceed US occupational dose limits for skin (3). Clearly the risk comes from inhalation, ingestion and the contamination of wounds with DU dusts or shrapnel caused by hard-target strikes. Three exposure levels have been determined. (Table 2) $(3,4)$. There are no known UK personnel who received Level I exposures but there may have been UK personnel who received Level II exposures in the course of clearing the battlefields.

\section{Environmental Assessments}

Development of DU munitions began in the

Table 2. Depleted Uranium Exposure Scenarios.

\begin{tabular}{|ll|}
\hline Level I & $\begin{array}{l}\text { Personnel in, or on, vehicles struck by } \\
\text { DU munitions or who entered in the } \\
\text { immediate aftermath, typically to rescue } \\
\text { injured occupants }\end{array}$ \\
\hline Level II & $\begin{array}{l}\text { Post-combat repair, salvage and } \\
\text { reclamation work on vehicles struck by } \\
\text { DU munitions }\end{array}$ \\
\hline Level III & $\begin{array}{l}\text { All other exposures such as being } \\
\text { downwind of DU-struck vehicles or brief } \\
\text { entry into such vehicles, resuspension of } \\
\text { dust from contaminated ground. }\end{array}$ \\
\hline
\end{tabular}


1970s and has involved test firings which continue in order to prove batches of ammunition. Environmental assessments of the impact of DU have been part of the development process. A number of US studies are referred to in the OSAGWI Environmental Exposure Report and the conclusion is that the development of DU munitions would probably have no significant environmental impact (3). Likewise in the UK, in order to conform to the European Community Environmental Assessment Directive, the Ministry of Defence commissioned an assessment of the environmental impact of DU munitions fired on proving ranges which failed to demonstrate marine, land or air contamination above background levels of uranium found elsewhere in the UK (7).

With regard to the use of DU in military operations, both the UN and the WHO have assessed the environmental impact following its use in Kosovo. The WHO mission concluded that elevated human health risks are unlikely to be attributable to NATO use of DU, but cautioned that quantitative information on environmental contamination was required to confirm this impression (5). The United Nations Environmental Programme (UNEP) carried out a field mission to Kosovo in November 2000 to assess the environmental impact of the use of DU by analysing soil, water and other samples from sites where DU rounds struck (8). It concluded that detectable widespread contamination had not occurred and that such contamination as was found occurred within a few metres of points of impact of DU munitions. No evidence of contamination of water, milk, buildings or other objects was found and even at impact points there was no significant risk of contamination of air, water or plants. It was felt that DU penetrators may well be buried some metres deep in the ground and that there was a potential risk that WHO limits for uranium in drinking water may be exceeded in the future at sites of heavy firing, although radiation risks would remain very low. Similar types of environmental assessment do not appear to have been conducted in Bosnia or the Gulf.

\section{Health Effects Of Uranium Exposure}

The most significant risk from exposure to DU arises from its toxological and radiological effects if it is internalised. Whilst external to the body, it does not pose a toxicological hazard and the radiological hazard is extremely small since the alpha particles produced by radioactive decay effectively do not penetrate the outer protective layer of dead cells in the stratum corneum of the skin. The amount of DU that the body absorbs will largely depend on the route of exposure, the solubility of the DU compounds to which one is exposed and other factors such as chemical form and, in the case of an aerosol, particle size.

There has been little specific work on the health effects of DU. What has been published is in relation to exposures resulting from the Gulf conflict. There has, however, been considerable research into the health effects of exposure to natural uranium. Given that the biochemical properties of natural uranium and DU are identical and that DU is about $40 \%$ less radioactive than natural uranium, the research into the health effects of exposure to natural uranium is valuable since it can be used to describe an upper boundary of the risk of adverse health effects from exposure to DU. Epidemiological studies on occupationally exposed groups including uranium miners, uranium millers and other miners have been reviewed in several major published works that examine the health effects of uranium $(2,6,9,1,4)$. Included are analytical studies where chronic exposures exceeded the current occupational exposure standards as well as case reports of large accidental acute exposures.

Once absorbed, uranium compounds that are soluble can be nephrotoxic like other heavy metals and the ATSDR regards the kidney as the most sensitive target organ. However, uranium is considered to be less nephrotoxic than the traditional heavy metal renal toxins (cadmium, lead and mercury)(1). Animal studies involving high dose exposures by oral, parenteral and inhalational routes reveal histological evidence of necrosis and atrophy of the tubular epithelium, thickening of the glomerular capsule wall, and shrinkage of the glomerular capillary network with resultant reduction in the glomerular filtration rate. These effects are also seen in humans when exposure to soluble uranium compounds is sufficiently large, but most of the epidemiological studies of uranium miners and mill workers have failed to show any unusual incidence of renal disease (2). It appears that an acute threshold dose is required to cause renal damage and, even then, the experiences from animal work, accidental human exposures and autopsy studies suggest that there is some capacity for spontaneous recovery.

The other organ with the greatest potential for damage is the lung. Human and animal evidence indicate that insoluble uranium compounds may remain in pulmonary tissues and mediastinal lymph nodes for many years, posing a long-term localised chemical and radiological hazard. Alpha radiation from DU particles could plausibly cause lung fibrosis but most large studies of uranium workers have not shown any substantial elevation in the risk of nonmalignant lung disease. The results of these studies are open to some interpretation however, because of the potential confounding effects of respiratory hazards 
including cigarette smoke. The Institute of Medicine concluded that there was inadequate or insufficient data to determine whether there was an association between other respiratory disease and uranium exposure (9).

Excessive incidences of lung cancer have been found in uranium miners, especially those who smoked, but not in other uranium workers. The reviews generally agree that the excesses of lung cancer in the miners are probably due to the confounding effect of exposure to radon gas and its daughters as well as other noxious substances present in mines. They also agree that uranium exposure has not resulted in increased mortality from all cancers. The ATSDR is particularly robust in making the statement that "no human cancer of any type has been seen as a result of exposure to natural or depleted uranium" (2).

With regard to other systems there is evidence of some minor changes in haematological parameters and transient gastro-intestinal and hepatotoxic effects based on small surveys and individual case reports. The evidence for immunological, reproductive, developmental, genetic, cardiovascular, dermal, ocular or musculoskeletal effects is less clear.

The Institute of Medicine concluded that there is limited/suggestive evidence of no association between exposure to uranium and lung cancer at cumulative internal dose levels lower than $200 \mathrm{mSv}$ (or 25cGy) or clinically significant renal dysfunction. It also concluded that there is inadequate/ insufficient evidence for an association with a range of other health outcomes (9). If one takes the linear, no threshold model of dose and stochastic effect used in radiation protection (10), one could expect a proportionate increase in the incidence of cancer following any radiation dose, however small. There is insufficient human data overall to confirm this dose-response relationship at low dose and low dose rates and the shape of the curve in these areas is a subject of much debate. The term 'hormesis' is even used to describe a controversial concept that minute doses of radiation have beneficial health effects (11). Nevertheless, if one accepts a consensus opinion of a positive doseresponse relationship without a threshold, then the true incidence of cancers in those exposed to uranium and studied in the past should have risen. If this was the case, the size of the rise is likely to have been so small compared with the natural incidence of cancer that this, in conjunction with the effects of confounders, probably explains why the effect was not detected.

\section{Veterans Illnesses And Depleted Uranium Research}

Gulf Veterans' Illnesses

Since the concerns about DU were first raised in relation to its use in the Gulf conflict there has been a decade of research into Gulf Veterans' Illnesses (GVI) and it is appropriate to summarise the major outcomes.

Following their return from the Gulf some veterans reported poorly-defined ill-health and the term 'Gulf War Syndrome' was coined. Apart from non-specific illness, there have been allegations of increased mortality among Gulf veterans and of birth defects among children born to Gulf veterans.

Initial responses involved the establishment of systematic clinical assessment programmes. In the UK, the Ministry of Defence established the Gulf Veterans' Medical Assessment Programme (MAP) in October 1993. In the US, the Department for Veterans Affairs Gulf Registry Health Examination Program (VA Registry) commenced assessing veterans who had left the services in 1992 and the Department of Defense set up the Comprehensive Clinical Evaluation Program (CCEP) in 1994 which assessed those Gulf veterans who were still serving. The UK programme operates from a single facility whereas the US programmes operate to a protocol at a number of sites. In both cases replicability of assessment is the key. The findings of these programmes have been published.

Coker published his initial findings from the MAP in 1996 (12). He found that veterans complained of a multiplicity of symptoms but not in a consistent pattern. Fatigue, musculoskeletal pain, irritability, memory loss and breathlessness were commonly described, but there was generally, an absence of physical signs and an absence of consistently abnormal laboratory investigation. Psychological conditions were diagnosed in $35 \%$ of those attending with the next largest group being Symptoms, Signs and Ill-Defined Conditions (SSIDC) and Chronic Fatigue Syndrome. In the selfselected series there was no clinical indication of any novel or uniquely Gulf related condition. The multiplicity of symptoms without any particular pattern, accompanying physical signs, or abnormal, laboratory findings is a feature of subsequent reports from the $\operatorname{MAP}(13,14)$, the CCEP(15) and the VA Registry (16). Not surprisingly psychological disorders, musculoskeletal conditions and SSIDC show a fairly consistent pattern across the early reports $(12,13,15,16)$ but Lee and colleagues, with the benefit of the greater experience and knowledge accruing from a decade of research and assessment, find that the majority of veterans are well and that SSIDC diagnoses virtually disappear.

Epidemiological research has also investigated GVI. There have been three large studies into the self-reported morbidity of Gulf veterans and a consensus has generally emerged $(17,18,19)$. In the US, 
the Iowa Persian Gulf Study Group surveyed a sample of just less than 5000 subjects representing regular and reserve forces deployed to the Gulf and regular and reserve forces who did not deploy (Era controls). The response rate was $76 \%$ and Gulf veterans reported 2-3 times as many symptoms and medical conditions as the Era group, as well as diminished physical functioning.

Fukuda and colleagues (1998) studied some 3700 subjects from four Air Force units. Some $31 \%$ had deployed to the Gulf, the rest comprised the Era group. The pattern of symptom reporting showed that Gulf veterans reported symptoms 3-4 times as frequently as the Era group. Using factor analysis, a case definition for a multisymptom disorder was developed and its prevalence among Gulf veterans was of the order of three times that amongst the Era group. Clinical evaluation of a sample of the study population failed to reveal clinically significant abnormalities on physical or laboratory examination.

Unwin and colleagues, compared random samples of British Gulf veterans with Era controls and a sample of British forces who deployed to Bosnia. Each sample group was about 4250 strong and in achieving a 65\% response rate the study found that Gulf veterans reported the same symptoms and medical conditions in the same rank order as the Era and Bosnia groups but 2-3 times more frequently. Virtually no differences in physical function were reported between the groups, but Gulf veterans reported a worse health perception than the comparison groups. Importantly, in the context of DU, responses from the Bosnia group were indistinguishable from that of the Era group, indicating that there was no health effect from deployment to that country. The Iowa and Unwin studies found weak associations between ill-health and a number of exposures but DU was not amongst them. These three large studies have shown that Gulf veterans report the same symptoms as the non-deployed but up to four times more frequently. Such clinical assessments that have been published in relation to these studies have confirmed the paucity of abnormal laboratory and physical examination results found in the clinical assessment programmes.

An outlier to the consensus is the work of Haley and colleagues. He found evidence of three factor derived Gulf syndromes on the basis of a small study in a single specialised Reserve unit (20). The study has been criticised for its small size (249 participants), poor response rates $(41 \%)$, and lack of controls $(21,22)$. Ismail and colleagues, also using factor analysis in their much larger study, failed to find epidemiological evidence of a unique, novel or Gulf-related syndrome (23).
All of the above studies into Gulf veterans' morbidity rely on self-reported data with all the limitations of that approach. Harder evidence has also been published. Kang and Bullman (1996) have demonstrated a small but significant excess of mortality in US Gulf veterans compared with non-deployed veterans over a $2^{1 / 2}$ year period of observation (24). The excess of deaths was mainly due to accidents rather than disease. They report that a similar picture was found following the Vietnam War. A mortality study on British veterans over an 8-year period also found an excess of deaths among Gulf veterans but the differences did not reach statistical significance (25). Again there were more accident and external cause- than diseaserelated deaths. A study of birth defects among children born to Gulf veterans showed no evidence of increased risk of birth defects although the period of observation was just three years and the study was restricted to births in military hospitals (26). A hospitalisation study of still serving US military personnel also showed no increase of unexplained hospitalisation in Gulf veterans in the 30 months after the end of the conflict (27).

Thus, at the present state of knowledge, it would seem that GVI could be characterised by multiple non-specific symptoms which are not generally associated with abnormal physical signs or clinical investigations, impairment of function or increased mortality and with little evidence of claimed excesses of adverse reproductive outcomes. The same pattern of findings has also been observed in Dutch soldiers on peacekeeping operations (28) and Hyams has traced similar precedents back to the US Civil War (29).

\section{Gulf Related DU Research}

During the Gulf conflict, the only use of DU munitions was by US and UK forces and any exposure was therefore "self-inflicted" either by friendly fire incidents or by exposure to targets hit by DU munitions. The US Department of Defense has currently identified approximately 160 US personnel who were either, in or on, vehicles struck by DU munitions or who participated in immediate rescue attempts and were thus potential candidates for Level I exposures (3). A programme to follow up these personnel was initiated in 1993 by the Baltimore Veterans Affairs Medical Center. In 1993, 48 of the 68 personnel then identified as having been on vehicles struck by DU munitions were traced and invited to participate in the follow-up programme and 33 agreed to participate. Hooper and colleagues assessed urinary uranium excretion and related it to DU exposure (30). Shrapnel status was assessed by radiological examination and four groups were identified: No suspected shrapnel, Self-report of 
shrapnel, Physician-suspected shrapnel and Confirmed shrapnel. In 1993, the group with confirmed shrapnel showed statistically significant elevations of urinary uranium excretion compared with the other three groups. Concentrations were about 150 times higher, the mean being $10.08 \mathrm{mcg} / \mathrm{L}$. The differences between the other three groups were statistically insignificant. In 1995, 20 of the original group were reassessed and their urinary uranium excretion remained highly elevated compared with the comparison groups whose differences were again indistinguishable.

In 1997, McDiarmid and colleagues attempted to compare health outcomes between personnel with Level I exposures and a non-exposed control group (31). Of the original 33 participants of the 1993 study 29 agreed to participate, of whom 14 had retained shrapnel. A comparison group of 38 non-DU exposed Gulf veterans was constructed of whom 22 completed the full evaluation. The groups were divided into high and low uranium groups on the basis of urinary uranium excretion and there was a continuing association between high urinary uranium excretion and retained DU shrapnel. A comprehensive history and clinical examination was undertaken with measurement of haematological and renal function parameters, neurocognitive evaluations and assessment of reproductive health and genotoxicity measures. Although some members of both groups had ongoing problems related to wounds received during the conflict, none of these could be related to the presence of uranium. No differences in renal function or haematological parameters were found between the two groups. The only differences that were found related to computerised tests of neurocognitive function, after traditional tests had revealed no differences, and an elevation of the serum prolactin in the high uranium excreting group towards the upper end of the normal range. The clinical significance of these findings remains obscure. Preliminary results of a 1999 follow-up were reported to a conference on Gulf war illnesses earlier this year and these minor aberrations had disappeared to be replaced by minor changes in haematological profiles which were now within the range of normal (32).

McDiarmid and colleagues have reported the results of a voluntary urinary uranium testing programme (33). In response to continuing concerns about DU, US Federal authorities offered a voluntary urinary uranium testing programme. By summer 2000, 265 Gulf veterans had submitted samples and completed exposure scenario questionnaires. Urinary uranium concentrations were split into low and high uranium groups and these were assessed against the offered exposure scenarios. Twelve of the submitted samples were in the high uranium group. Of these, seven personnel submitted second samples and four of the repeat sample results were in the low uranium group. Of the three that remained in the high group, one never deployed to the Gulf or had any known DU exposure and the authors suggested possible, transient dietary intakes or laboratory technical issues as a cause. Attempting to link self-reported exposure scenarios to results showed that no scenario had significant specificity, sensitivity or predictive value related to a high urinary uranium result. This portfolio of research suggests that, despite small numbers, there is a correlation between elevated urinary uranium concentration and the presence of DU shrapnel and that no adverse health effects due to the presence of DU have been observed. This latter finding is in keeping with the review material quoted earlier.

Experimental work has indicated the possibility that DU can invoke mutagenic change. Miller and colleagues have shown that serum and urine from rats implanted with DU pellets can induce mutagenic activity using the Ames Salmonella reversion assay (34). The ability to transform human osteoblast cells to a tumorigenic phenotype has also been demonstrated in laboratory experiments using cell lines exposed to a DU compound (35). Finally preliminary data presented at a conference has shown evidence of sarcoma development in rats implanted with DU plates (36). Groups of 50 rats were implanted with DU in the form of plates of varying size or pellets. Tantalum plates and Thorotrast were used as controls and a further control using a surgical procedure without implantation was adopted. Radiological studies showed evidence of corrosion of the DU fragments and proliferative tissue reactions around all the metal implants but not the Thorotrast. At post-mortem, soft tissue sarcomas were found in the tissue reactions around some of the DU plates but not the pellets and around some of the tantalum plates but not the surgical controls. It was suggested that it may be prudent to follow up military personnel with embedded DU as a result of these findings.

\section{Management Of Casualties Exposed To DU}

Immediate Care

The adverse health effects that may occur following DU exposure are all relatively insignificant compared with the potential effects of the life and limb threatening injuries that occur in battle. Standard battlefield advanced trauma life support techniques are therefore appropriate for these injuries and there is no reason to change policies on immediate and surgical management on the basis that a casualty may have been exposed to DU. After controlling shock and haemorrhage, the strenuous 
efforts taken routinely to prevent wound infection, such as wound excision and delayed primary closure, will reduce contamination by DU and other contaminants.

In some other situations and settings where wounds are contaminated with radioisotopes, such as wound contamination by plutonium in industry, the use of special wound probes to detect contamination and decontamination techniques such as the local application of a chelating agent may be indicated (37).

Personnel involved in the rescue, evacuation and/or immediate care of casualties that may have been exposed to DU do need to be aware of the means by which particles of DU oxides may present a hazard to their health. Personnel entering a vehicle struck by a DU round may inhale particles of DU oxides formed in the strike and any personnel handling casualties thereafter may be exposed due to re-suspension then inhalation of particles from the casualties' clothes, skin and hair. Nevertheless, in considering the merit of providing swift, quality care to battle casualties against the additional exposure of other personnel to DU that this action would entail, the risks to rescuers and health care personnel should be so small in comparison with the benefits to casualties that there should be no question that exposures are not justified. However, after assessing all the risks of operating at or near the front line of battle separately and in conjunction with each other, any means of controlling this exposure should be used when reasonably practicable and when appropriate. This accords with standard principles of occupational health and safety. A number of simple control measures may be warranted. Sheets or blankets could be used during the transport of casualties to minimise spread of contamination. Casualties could be undressed using techniques to minimise re-suspension of contaminants and administrative controls, such as sectioning a medical facility into 'dirty' and 'clean' areas along with bans on smoking, drinking and eating could all be appropriate. Personnel can be taught about the hazard posed by DU so that they know how to minimise their own exposure and, as a final control, the use of respiratory protective equipment such as industrial dust masks could be appropriate until after casualties have been undressed and washed.

\section{Longer Term Care}

An individual's history can allow his or her exposure to DU to be categorised into one of several levels already described (Table 2). Knowledge gained from occupational hygiene measurements and studies of exposure situations also allow a quantitative estimate of exposure. In some situations where individuals are either suspected to have been contaminated with radioisotopes or confirmed to have been contaminated as shown by urine, stool or other monitoring techniques, interventional therapies known as decorporation treatments may be considered $(38,39)$. These interventions aim to reduce both the dose and the dose rate, but they do carry some inherent risk, which needs to be balanced against their potentially beneficial effects. Broncho pulmonary lavage can be a valuable treatment following inhalation of relatively insoluble radionuclides but the risks from the procedure, which involves a general anaesthetic, are immediate whereas the stochastic effects of radiation only occur many years later. Realistic assumptions about the maximum quantity of DU that can be inhaled in military exposure scenarios together with the relatively low activity of DU almost certainly mean that this technique will be inappropriate, even for the personnel with the highest exposures. Uranium complexation by sodium bicarbonate and chelation with DTPA (diethylene-triamine-pentaacetic-acid) are other potential decorporation treatments that are sometimes considered for exposures to uranium isotopes. However the efficacy, of both is questionable (39) and no recommendations can be made about their use in military DU exposure scenarios where the overall magnitude of the risk of ill-health following exposure seems to be small.

With regard to continuing care of casualties with the greatest potential exposure to DU, survivors from hard targets struck by a DU penetrator, the limited evidence available suggests that measurement of urinary uranium excretion is probably a good indicator of the presence of retained DU shrapnel. There is, however, no evidence so far that such shrapnel is a cause of adverse health effect in human battle casualties. Shrapnel fragments, of DU or other metals, may have been localised by radiographs or other imaging techniques conducted as part of routine care or follow up. Even though no adverse health effects have been shown, some consideration should be given to following up these patients, or even removing the fragments by elective surgery simply as a precautionary measure. Ultimately, decisions about the appropriateness of these actions need to be made on a case by case basis, taking into account the results of emerging research, but elective surgical removal may be appropriate when fragments are large, the surgical risks are minimal and the individual casualty expresses a high level of concern. Personnel receiving Level II or lower exposures may benefit from risk communication and individual testing of urinary uranium excretion may be appropriate in isolated cases based upon clinical need. Large scale screening programmes looking either for the 
presence of DU or for DU related health effects are not indicated.

\section{Conclusions}

The comprehensive reviews cited have shown the potential for uranium to cause renal damage and damage to the lung including the development of lung cancer. Epidemiological studies of occupationally exposed groups of workers and case reports involving accidental exposures to uranium both acute and chronic which exceed set occupational limits have failed to demonstrate either increased all-cause or cause-specific mortality due to exposure to uranium or indeed increased prevalence of diseases attributable to uranium among the exposed. Studies on the small numbers of Gulf veterans known to have received Level I exposures to DU have failed to demonstrate either any evidence of retained DU (except in those with retained shrapnel) or any adverse health effects due to DU. Animal studies show the potential for mutagenic change and carcinogenesis which has not been demonstrated in the human experience of uranium or DU exposure.

On the basis of these findings the risk of harm following DU exposure in military settings seems to be low. Military personnel involved in rescue and initial treatment of casualties should take reasonable precautions to minimise their exposure when these are practicable without compromising the immediacy or quality of casualty care. There is no indication to adopt a different approach to their role of rescue and battlefield advanced trauma life support. With regard to long term care, it may be prudent to follow up the most exposed groups of personnel, those with retained DU shrapnel. These personnel may also act as a cohort for ongoing medical research into the effects of DU exposure on health.

\section{References}

1. World Health Organization (WHO (1)). 2001. Depleted Uranium: sources, exposure and health effects. Department of Protection of the Human Environment, World Health Organization, Geneva.

2. Agency for Toxic Substances and Disease Registry (ATSDR). Toxicological profile for uranium (Update). 1999. US Department for Health Human Services. Atlanta, Georgia.

3. Office of the Special Assistant for Gulf War Illness (OSAGWI). 2000. Environmental Exposure Report: Depleted Uranium in the Gulf (II). Department of Defense, Washington DC. www.gulflink.osd.mil

4. The Royal Society. 2001. The health hazards of depleted uranium munitions part 1. London.

5. World Health Organization (WHO (2)) 2001. Report of the World health Organization Depleted Uranium Mission to Kosovo.

6. Harley NH, Foulkes EC, Hilborne LH, Hudson A and Anthony CR. 1999. A review of the scientific literature as it pertains to Gulf war illnesses, volume 7: depleted uranium. The Rand Corporation, Washington DC.

7. WS Atkins, Consultants. Environmental assessment of firing of depleted uranium projectiles at Eskmeales and Kircudbright ranges. 1995. Ministry of Defence.

8. United Nations Environmental Programme
(UNEP) Report. 2000. Depleted Uranium in Kosovo: Post-Conflict Environmental Assessment. United Nations, Switzerland.

9. Fulco CE, Liverman CT and Sox HC. 2000. Gulf War and Health, Volume 1: depleted uranium, pyridostigmine bromide, sarin, vaccines. Institute of Medicine, National Academy Press, Washington DC. www.nap.edu.

10. ICRP Publication 60. 1990 Recommendations of the International Commission on Radiological Protection. Ann ICRP 1990; 21(1-3): 16-21.

11. Mettler FA, Upton AC. 1995. Medical Effects of Ionizing Radiation. WB Saunders Company: Philadelphia, 385-387.

12. Coker WJ. A review of Gulf war illness. $\mathcal{F} R \mathrm{Nav}$ Med Serv1996; 82: 141-146.

13. Coker WJ, Bhatt BM, Blatchley NF and Graham JT. Clinical findings for the first 1000 Gulf war veterans in the Ministry of Defence's medical assessment programme. Br Med F 1999; 318: 290294.

14. Lee HA, Gabriel R, Bale AJ, Bolton $P$ and Blatchley NF. Clinical findings of the second 1000 UK Gulf War veterans who attended the Ministry of Defence's medical assessment programme. $\mathcal{F} R$ Army Med Corps 2001; 147: 153-160.

15. Joseph SC and the Comprehensive Clinical Evaluation Program Evaluation Team. A comprehensive clinical evaluation of 20,000 Persian Gulf war veterans. Military Medicine 1997; 162(3): 149-155.

16. Murphy FM, Kang H, Dalager MS, Lee KL, Allen RE, Mather SH et al. The Health Status of Gulf Veterans: Lessons Learned From the Department of Veterans Affairs Health Registry. Military Medicine 1999; 164(5): 327-331.

17. Iowa Persian Gulf Study Group. Self-reported illness and health status among Gulf war veterans: A population-based study. $7 A M A$ 1997; 277(3): 238245.

18. Fukuda K, Niesenbaum R, Stewart G et al. Chronic multisymptom illness affecting Air Force veterans of the Gulf war. FAMA 1998; 280(11).

19. Unwin C, Blatchley N, Coker W, Ferry S, Hotopf M, Hull L et al. Health of UK Servicemen who served in Persian GulfWar. Lancet 1999; 353: 169178.

20. Haley RW, Kurt TL and Horn J. Is there a Gulf war syndrome? $\mathcal{F} A M A$ 1997; 277(3): 215-222.

21. Landrigan PJ. Illness in Gulf war veterans. Causes and consequences. $\mathcal{F} A M A$ 1997; 277(3): 259-261.

22. Ferrari R and Russell AS. The problem of Gulf war syndrome. Med Hypotheses 2001; 56(6): 697-701.

23. Ismail K, Everitt B, Blatchley N, Hull L, Unwin C, David A et al.. Is there a Gulf war syndrome?. Lancet 1999; 353: 179-182.

24. Kang HK and Bullman TA. Mortality among US veterans of the Persian Gulf war. $N$ Engl $\mathcal{F ~ M e d ~}$ 1996; 335(20): 1498-1504.

25. Macfarlane GJ, Thomas E and Cherry N. Mortality among UK Gulf war veterans. Lancet 2000; 356: 7-21.

26. Cowan DN, DeFraites RF, Gray GC, Goldenbaum MB and Wishik SM. The risk of birth defects among children of Persian Gulf War veterans. N Engl f Med 1997;

27. Gray GC, Coate BD, Anderson CM, Kang HK, Berg SW, Wignall FS et al. The postwar hospitalisation experience of US veterans of the Persian Gulf war. $N$ Engl $\mathcal{f}$ Med 1996; 335(20): 1505-1513.

28. De Vries M, Soetekouw PMMB, Van Der Meer JWM and Bleijenberg G. Natural course of symptoms in Cambodia veterans: a follow-up study. Psychol Med 2001; 31: 331-338.

29. Hyams KC, Wignall FS and Roswell R. War syndromes and their evaluation: From US Civil War to the Persian Gulf war. 1996. Ann Intern Med, 125(5), 398-405.

30. Hooper FJ, Squibb KS, Siegel EL, McPhaul K and Keogh JP. Elevated urine uranium excretion by soldiers with retained uranium shrapnel. Health Phys 1999; 77(5): 512-519. 
31. McDiarmid MA, Keogh JP, Hooper FJ, McPhaul $\mathrm{K}$, Squibb $\mathrm{K}$, Kane $\mathrm{R}$, et al. Health effects of depleted uranium on exposed Gulf war veterans. Environ Res 2000; 82: 168-180.

32. McDiarmid MA. Medical surveillance results in $D U$ exposed Gulf war veterans. Conference on Illnesses Among Gulf War Veterans: A decade of research. Military and Veterans Health Co-ordinating Board, Alexandria, Virginia, 24-26 January 2001.

33. McDiarmid MA, Engelhardt SM, Oliver M and Squibb K. Utility of self-reported exposure scenarios to depleted uranium in predicting elevated urinary uranium concentrations in Gulf war veterans. European fournal of Oncology 2001; 6(1): $55-60$

34. Miller AC, Fuciarelli AF, Jackson WE, Ejnik EJ, Emond C, Strocko S, et al. Urinary and serum mutagenic studies in rats implanted with depleted uranium or tantalum pellets. Mutagenesis 1998; 13(6): 643-648.

35. Miller AC, Blakely WF, Livengood D, Whittaker T, $\mathrm{Xu}$ J, Ejnik JW et al. Transformation of human osteoblast cells to tumorigenic phenotype by depleted uranium-uranyl chloride. Environ Health Perspect 1998; 106(8): 465-471.

36. Hahn FF, Guilmette RA and Hoover MD. 2001. Depleted uranium fragments cause soft tissue sarcomas in the muscles of rats. Conference on Illnesses Among Gulf War Veterans: A decade of research. Military and Veterans Health Co-ordinating Board, Alexandria, Virginia.

37. Bhattacharyya $\mathrm{MH}$, Argonne IL, Brieitenstein BD et al. Guidebook for the Treatment of Accidental Internal Radionucleide Contamination of Workers. Radiat Prot Dosimetry 1992; 41(1): 21. 336(23): 1650-1656.

38. NRCP Report No 65. Management of Persons Accidentally Contaminated with Radionuclides. 1980. National Council on Radiation Protection and Measurements. Bethesda, 125-158.

39. Hengé-Napoli MH, Stradling GN, Taylor DM eds. Decorporation of Radionuclides from the Body. Radiat Prot Dosimetry 2000; 87(1): Special issue. 